wrdered the child to be placed in bed and surrounded by hot water bottles, and injected subcutaneously twenty-five minims of sulphuric ether. The child gradually rallied, and the after treatment consisted in washing the mouth out with glycerine of borax and the administration of the following mixture : Ten minims of tincture of opium, half a drachm of bromide of potassium, half a drachm of chlorate of potassium, one drachm of bicarbonate of soda, one drachm of sub nitrate of bismuth, one ounce of acacia mucilage, water to two ounces. One drachm of the mixture was allowed to trickle down the throat, a few drops at a time, every two hours. An enema, consisting of one drachm of brandy, two arachms of starch, and three ounces of beef-tea, was given, but as this appeared to distress the patient it was discontinued, and zyminised nutrient suppositories substituted every four ibours. On July 4th the temperature rose to $101^{\circ}$, and as the patient was unable to swallow even a few drops of water the mixture had to be discontinued and hypodermic injections of morphia (one-fifteenth of a grain) given every five hours, whilst to cope with the thirst an enema of cold water was given every two hours, which gave great relief to the patient. On the 6th there was a decided improvement, and this continued up to the $18 \mathrm{th}$, when the patient was discharged well. H.M. Hospital, Carriacou, West Indies.

\section{ICHTHYOL IN ECZEMA.}

BY J. K. TOMORY, M.B., C.M. EDIN.

THE patient first came under my care in July, 1894, when I obtained the following history. About three years previously whe showed symptoms of an eczematous eruption on the back of the neck, which gradually spread up to the scalp amongst ger hair. She had the hair on the back of her head cut short, and the medical man whom she consulted prescribed an ointment for local application, as well as Fowler's solution to be taken internally. From that time she had never been entirely free from the eraption, and she had taken a considerable quantity, doubtless, of the usual remedies, but the eczema had never quite disappeared, though at times (especially when she was pregnant) it was less troublesome than at others. There is no trace of the disease in other members of her family. The eczema was very much worse in the spring. She had repeatedly taken arsenic and had applied starch poultices and a creamy looking ointment to the eruption. In July she consulted me, when I told her to have her hair cut again, and after one application of a starch and boracic poultice I ordered the following ointment to be applied night and morning : one ounce of ointment of oleate of zinc, half an ounce of ointment of oleate of mercury ( 20 per cent.), boracic acid ointment to six ounces; and prescribed half an ounce of this mixture to be taken after food : one ounce of the compound syrup of hypophosphites, forty-eight minims of Fowler's solution, water to eight ounces. The ointment allayed the itchiness, but otherwise it did not improve her condition. In September she consulted me again and I resolved to try ichthyol. I obtained a supply of camphoid ichthyol and gave the patient the following instructions (at this time I may say that there were considerable inflammation of the skin at the back of the neck and numerous patches of eczematous eruption extending beyond the occipital protuberance) : the head and neck were to be well washed with soft soap to remove any of the previous ointment, and at might a starch poultice was to be applied. The next morning the ichthyol was to be applied, and it was to be renewed once a day. On the day preceding the application I ordered her to have her hair well brushed, and this has been done every day since. There was absolutely no other treatrent given, and by the end of a month the skin of the neck was quite normal, and only one or two small spots could be seen on her head. By Nov. 10th she was absolutely free from all traces of the eczema, and has continued so ever since, but she keeps a supply of the ichthyol in order to apply it should any reappearance of her trouble manifest itself.

I have had considerable experience in the treatment of eczema, but I never had a case so intractable. In fact, I have been able usually to check it by means of the following lotion : two ounces of oxide of zinc, one ounce of boracic acid, half an ounce of subnitrate of bismuth, olive oil to twelve ounces; with the use of arsenic internally when the inflammatory symptoms had subsided. One of the severest cases of eczema I ever saw was cured after about six weeks" treatment with the above.

Halkirk, Caithness.

ENORMOUS SIZE OF THE RIGHT KIDNEY IN A. CHILD FOUR YEARS OF AGE.

BY E. G. BULlEID, L.P.C.P., L.R.C.S. EDIN.

ON the morning of Nov. 30th last I was called at $2.30 \mathrm{~A} . \mathrm{M}$. to see a boy four years of age who was said to be dying. On my arrival I found him in a comatose state, which was followed by convulsions until his death at 5 A.M. I was told by his parents that at 1 A.M. he was awake and as lively as usual. At the coroner's request I made a necropsy, and found the right kidney enlarged to an enormous size (weighing $25 \mathrm{oz}$.). The kidney substance was thoroughly disorganised; the capsule was almost one-eighth of an inch in thickness; it was oval in shape, very hard, and on section proved by examination to be a sarcoma. Now in this case the boy had no pain, never had (as far as his parents knew) any hæmaturia, and was considered a strong child, attending school regularly. They certainly noticed that he had become thinner duxing the previous six weeks, but beyond that no other symptoms were revealed.

I have ventured to report this case on account of its rarity, not having read of any case where the kidney had attained such a size without showing some outward sign of being a growth in the region of the kidney.

Southwick-street, w.

\section{S. Athror}

\section{H O S P I T A I P A C T I C E, BRITISH AND FOREIGN.}

Nulla autem est alia pro certo noscendi via, nisi quamplurimas et mor borum et dissectionum historias, tum aliorum tum proprias collectas habere, et inter se comparare.-MongAGNI De Sed. et Caus. Morb.. lib. iv. Procemium.

\section{MIDDLESEX HOSPITAL.}

A CASE OF LANDRY'S PARALYSIS.

(Under the care of Dr. Douglas Powwll.)

THE disease, of which the following case is a good example, known as acute ascending paralysis was described by Landry in 1869. It is not often seen in our hospital wards, and we are still doubtful as to its causation and pathology. "The progress, duration, and event of the disease vary. It is generally fatal, death resulting from the usual consequences of bulbar paralysis. The paralysis may become general and destroy life in the course of: two or three days. Occasionally the progress of paralysis is much slower, and death is delayed until the end of the third or fourth week." For the notes of the case we are indebted to Dr. H. Campbell Thomson, house physician.

A woman aged thirty-nine years was admitted to the hospital on July 14th, 1894, complaining of loss of power in the body and limbs. There was nothing of importance in the family history, and her previous history was one of good health ; she had had three normal confinements, and up to the time of her illness had been suckling for nine months. On Sunday night, July 8 th, the patient complained of a headache, which became worse the next day, and on the afternoon of July 9th there was great aching over the upper part of the back, and the patient commenced to retch. Retching and vomiting frequently occurred during the next two days, after which it passed off. On Jaly 10 th the patient noticed some sensation of tingling and numbness in the hands, which was followed in a few hours by similar seriations in the feet, and with the onset of numbness there was some loss of power both in the legs and arms. On July $11^{\text {th }}$ the numbens reached as high as the knees and loss of power was well marked. On July 13th there was very marked loss of power, but the patient was still able to pull herself up in bed. There 